\title{
La venta de insumos médicos y su repercusión dentro de la defraudación tributaria
}

The sale of medical supplies and its impact on tax fraud

\author{
Myriam Valeria Ruiz-Salgado \\ ur.myriamruiz@uniandes.edu.ec \\ Universidad Regional Autónoma de los Andes, Riobamba \\ Ecuador \\ https://orcid.org/0000-0002-4057-8427 \\ Christel Renata Peñaherrera-Calle \\ dr.christelrpc76@uniandes.edu.ec \\ Universidad Regional Autónoma de los Andes, Riobamba \\ Ecuador \\ José Miguel Llerena-Ramírez \\ dr.josemlr54@uniandes.edu.ec \\ Universidad Regional Autónoma de los Andes, Riobamba \\ Ecuador
}

Recibido: 31 de octubre de 2020

Revisado: 10 de octubre de 2020

Aprobado: 05 de diciembre de 2020

Publicado: 10 de diciembre de 2020 


\title{
RESUMEN
}

La investigación se centró en analizar la venta de insumos médicos y su repercusión dentro de la defraudación tributaria en el Ecuador. Metodológicamente es de carácter descriptiva documental con diseño bibliográfico no experimental, se trabajó con una muestra poblacional de 65 usuarias de los servicios de salud pública en medio de la pandemia por COVID - 19. El 65\% de las personas encuestadas coinciden en que se debería fortalecer o endurecer las penas sobre los delitos de corrupción con bienes públicos tomando, así como interpretación que las y los ciudadanos encuestados ven viable que esta sea la solución. Al analizar el marco legal ecuatoriano se pudo evidenciar que existen una gran cantidad de leyes las cuales reconocen y garantizan la defraudación tributaria las cuales respaldan que el sobre precio en los insumos médicos y su repercusión en la sociedad cuando estos son revendidos o supuestamente comprados a un precio elevado.

Descriptores: Tributación; hacienda pública; derecho civil. (Palabras tomadas del tesauro UNESCO).

\begin{abstract}
The investigation focused on analyzing the sale of medical supplies and its impact on tax fraud in Ecuador. Methodologically, it is of a descriptive documentary nature with a non-experimental bibliographic design, we worked with a population sample of 65 users of public health services in the midst of the COVID-19 pandemic. $65 \%$ of the people surveyed agree that it should be strengthened or toughen the penalties on corruption crimes with public goods taking, as well as interpretation that the surveyed citizens see viable that this is the solution. When analyzing the Ecuadorian legal framework, it was possible to show that there are a large number of laws which recognize and guarantee tax fraud, which support the over-price of medical supplies and its impact on society when they are resold or supposedly bought from a high price.
\end{abstract}

Descriptors: Taxation; public finance; civil law. (Words taken from the UNESCO thesaurus). 
Iustitia Socialis. Revista Arbitrada de Ciencias Jurídicas.

Año V. Vol. V. №3. Edición Especial. 2020-III:

Universidad Regional Autónoma de los Andes

Hecho el depósito de Ley: FA2016000064

ISSN: 2542-3371

FUNDACIÓN KOINONIA (F.K). Santa Ana de Coro, Venezuela

Myriam Valeria Ruiz-Salgado; Christel Renata Peñaherrera-Calle; José Miguel Llerena-Ramírez

\section{INTRODUCCIÓN}

Este es un estudio direccionado a poder evidenciar cual ha sido el desempeño, labor, función, incompetencia y resultado de la "venta de insumos médicos y su repercusión dentro de la defraudación tributaria" siendo así que se emplean mecanismos que afectan de manera directa el buen desarrollo de los recursos y servicios públicos. Para ello se consideran de manera vital conocer cuál es la marco normativa vigente que delimite cuales son las características que poseen, las prohibiciones y sanciones que se pueden imponer refiriéndose al tema propuesto, la Constitución de la República del Ecuador, el Código Tributario y el Código Orgánico Integral Penal, son normativas de uso requerido y directo para la elaboración de nuestro artículo, es muy importante recalcar que este estudio se desarrollara en base a la actualidad que vive el país en tiempos de pandemia y emergencia sanitaria.

A medida que la sociedad se ha ido desarrollando en el contexto de la distribución inexacta de los recursos públicos, la falta de ética por parte de los tipos de servidores públicos que incurren en este delito tanto normado y penado por la ley como a su vez mal visto y desaprobado por la sociedad, desembocando en un interés común para el beneficio de unos pocos siendo así que la distribución y venta de los insumos médicos en tiempos de pandemia y emergencia sanitaria se ve brutalmente afectada e impide de manera directa y en demasía el correcto desarrollo de los estándares de emergencia que se deberían desarrollar en un tiempo así, esto sin más evidencia que el estado y sus mandos medios no funcionan en su trabajo en conjunto y que la sociedad servil publica carece de medios de fondo, forma y preparación para poder desempeñar de manera integral un cargo o labor que se le ha designado. (Peña, 2013). Así mismo, Castro (2020), indica que:

Según la información del 20 de marzo del presente año, el Ministerio de Salud Pública informó que tiene más de 42 mil batas quirúrgicas, cerca de 10 millones de guantes para examinación y guantes quirúrgicos, un millón de mascarillas quirúrgicas y 44 mil mascarillas N95. Sin embargo, el Ministerio no especifica si esa cantidad es suficiente para todos los profesionales de salud que trabajan en los hospitales públicos y están atendiendo la emergencia sanitaria. En una rueda de prensa virtual del 20 de marzo de 2020, la entonces ministra de Salud, Catalina Andramuño dijo que, desde enero de 2020, los hospitales tienen el presupuesto asignado 
para comprar insumos de protección. "Tiene abastecimiento por tres meses" por parte de funcionarios médicos, administrativos no autorizados o personas externas será remitidos a la Fiscalía General del Estado, para que se investigue el grado de responsabilidad a la que puede conllevar la alteración a la seguridad nacional". Iván Cevallos, exdirector del HCAM y docente de la Universidad San Francisco de Quito, opina que los comunicados enviados a los trabajadores del hospital son una amenaza directa, "es un atropello a la libertad de expresión". Cevallos dijo que ha tenido contacto con enfermeras, médicos, personal de limpieza, de lavandería y administrativos del hospital, "todos tienen claro que les falta atención".

La nota de prensa, denota una controversia sobre el manejo adecuado de los recursos hospitalarios, siendo afectado los pacientes que requieren contar con un servicio de calidad en aras de tener mayor posibilidad de superar afecciones, entre las cuales se encuentra el COVID-19, así mismo, el personal de salud, considera inoportuno, la manera como se desarrolla la advertencia o reclamo para sensibilizar sobre el manejo efectivo de los insumos médicos.

En cuanto a la penalidad por evasión tributaria, (De-La-Torre-Lascano, 2017), expone que existe confrontación doctrinal, sobre considerar este delito como parte del lavado de activos, siendo considerada la figura del contador como autor de la defraudación en consideración a la responsabilidad civil, siendo necesaria la profundización legislativa del tema de evasión en consideración de generar directrices que permitan desarrollar un proceso jurídico apegado a las normativas legales en razón de tramitar un castigo acorde a quienes formulen el delito de evasión o fraude tributario.

En este sentido, (Haro-Velastegui, et al., 2019), consideran que el delito de fraude fiscal es uno de los de mayor complejidad en suprimir, por cuanto, bien sea por desconocimiento o por conductas anti éticas se promueve tal afección sobre la sociedad, siendo esto concomitante con la actual investigación en donde se genera un perjuicio en contra de la sociedad ecuatoriana al estar en peligro el recibir un servicio de salud en calidad de los insumos que se requieren para ser atendidos por el personal en las instalaciones sanitarias.

En razón de lo planteado, la actual investigación se centró en analizar la venta de insumos médicos y su repercusión dentro de la defraudación tributaria en el Ecuador. 


\section{MÉTODO}

La presente investigación metodológicamente es de carácter descriptiva documental con diseño bibliográfico no experimental, se trabajó con una muestra poblacional de 65 usuarias de los servicios de salud pública en medio de la pandemia por COVID 19 en el Ecuador, a quienes se les aplicó encuesta online y cuestionario de diversas alternativas de respuestas, siendo validado por juicio de tres expertos y cálculo de Alfa de Cronbach con resultado de 0,86 siendo calificado como apto para su aplicación. Para el análisis de la información se procesó a través de la estadística descriptiva y análisis de contenido analítico.

\section{RESULTADOS}

Se presentan los siguientes resultados:

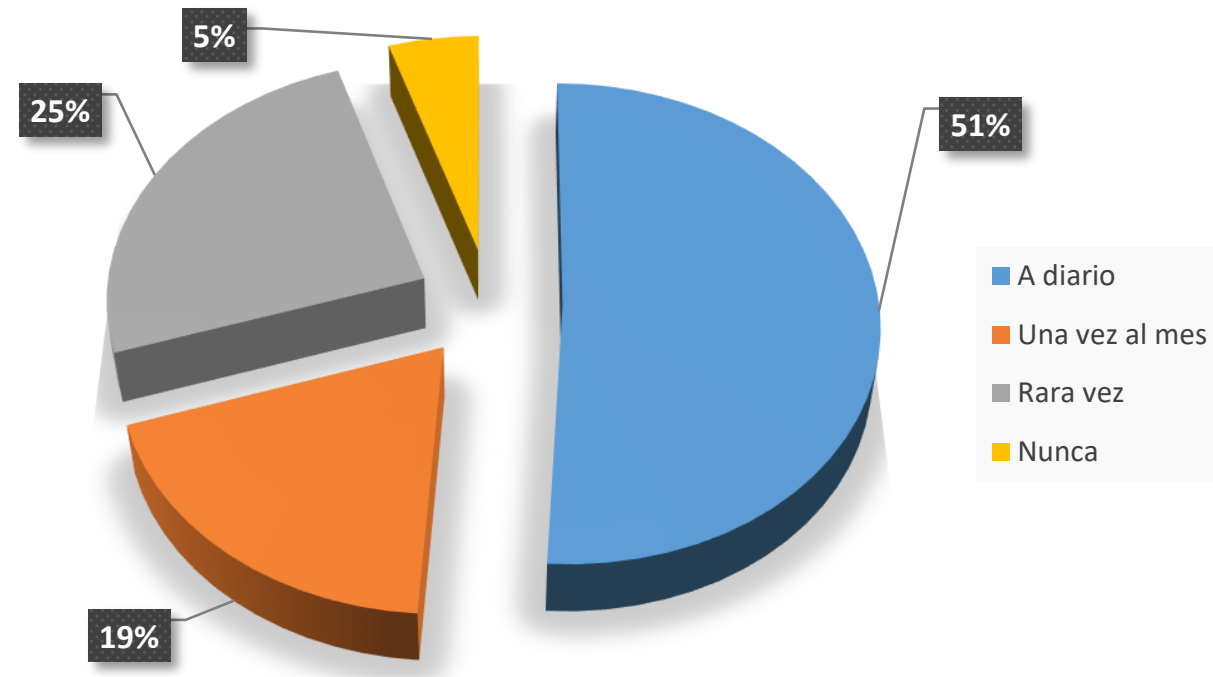

Gráfico 1. ¿Con que frecuencia usted ha escuchado sobre casos en los que se comercializa bienes públicos?

No todas las personas encuestadas tienen un conocimiento actualizado sobre los casos en los que se comercializan bienes públicos, esto podemos interpretarlo como un factor por lo cual se desconoce este tipo de actos ilícitos. 
lustitia Socialis. Revista Arbitrada de Ciencias Jurídicas.

Año V. Vol. V. №3. Edición Especial. 2020-III:

Universidad Regional Autónoma de los Andes

Hecho el depósito de Ley: FA2016000064

ISSN: 2542-3371

FUNDACIÓN KOINONIA (F.K). Santa Ana de Coro, Venezuela

Myriam Valeria Ruiz-Salgado; Christel Renata Peñaherrera-Calle; José Miguel Llerena-Ramírez

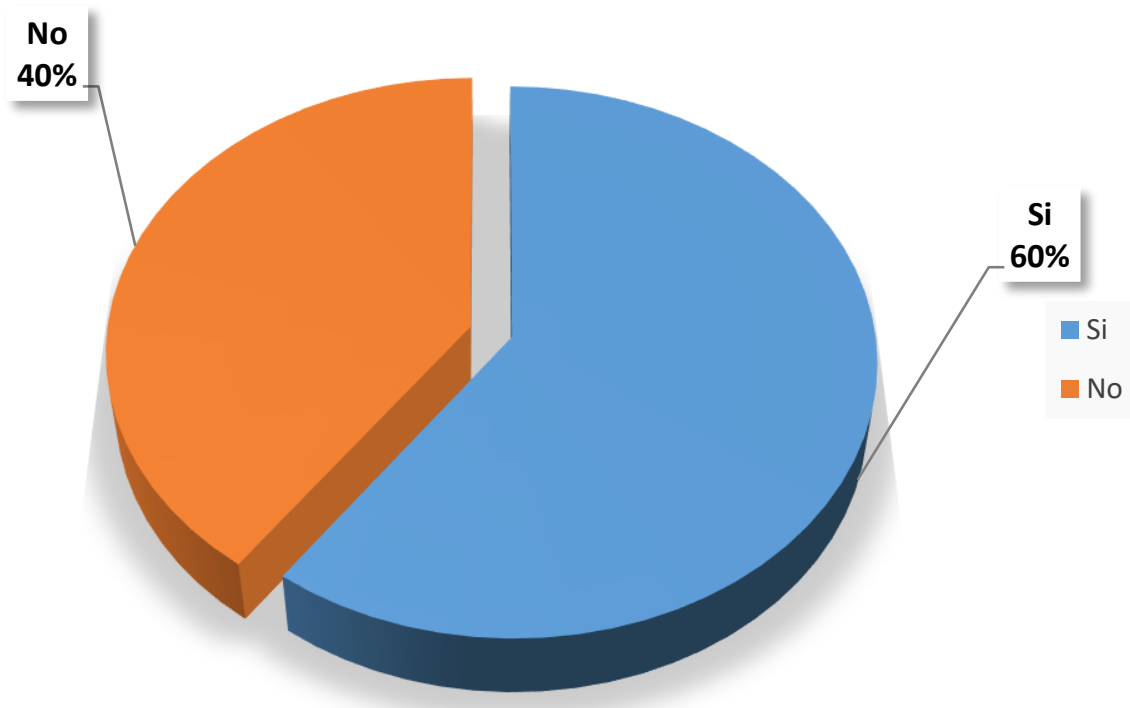

Gráfico 2. ¿Cree usted que las medidas que tomó el gobierno para combatir los casos de corrupción son las correctas?

El $60 \%$ de las personas encuestadas coinciden en que las medidas que tomó el gobierno en torno a combatir los casos de corrupción no son las medidas correctas, interpretando así el desacuerdo ciudadano con las decisiones del gobierno.

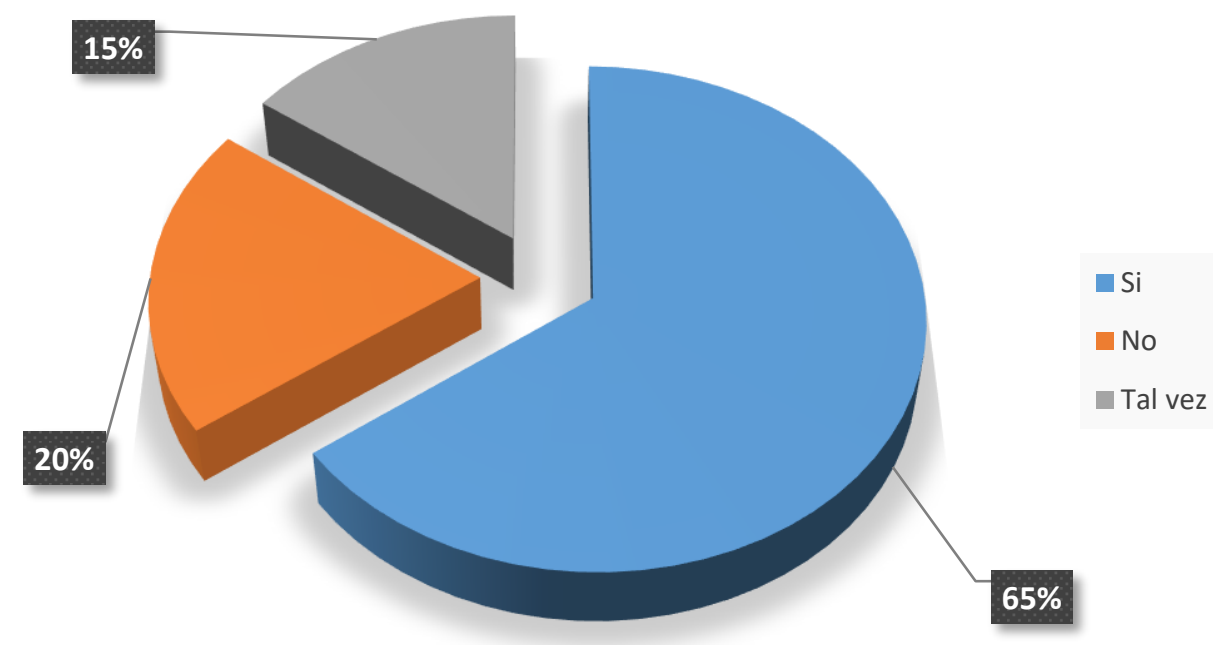

Gráfico 3. ¿Usted como ciudadano/a cree viable que se endurezcan las penas sobre estos delitos? 
Myriam Valeria Ruiz-Salgado; Christel Renata Peñaherrera-Calle; José Miguel Llerena-Ramírez

El $65 \%$ de las personas encuestadas coinciden en que se debería fortalecer 0 endurecer las penas sobre los delitos de corrupción con bienes públicos tomando, así como interpretación que las y los ciudadanos encuestados ven viable que esta sea la solución.

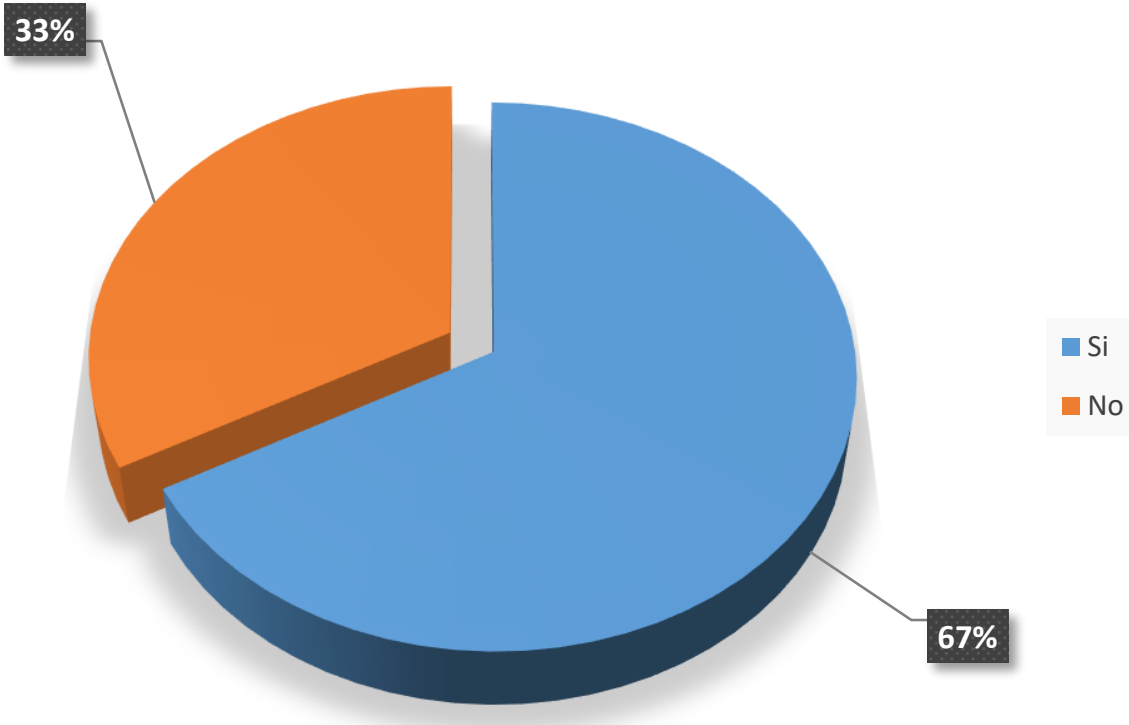

Gráfico 4. ¿Conoce usted que es una defraudación tributaria?

El 67\% de las personas encuestadas coinciden en que conocen de qué se trata una defraudación tributaria, esto refleja que las personas tienen el vasto conocimiento para entender de qué se trata la misma y a su vez que tienen un grado de estudio que así lo sustente.

\section{Resultados documentales}

1. El nuevo ministro de Salud, Juan Carlos Zevallos dijo en su primera rueda de prensa virtual que el Ecuador tiene 121 millones de dólares para enfrentar la emergencia. Ese dinero se invertirá para la compra de insumos médicos y equipos de protección para el personal de salud pública y otras acciones como habilitación de hospitales ambulatorios, dijo Zevallos. 
Myriam Valeria Ruiz-Salgado; Christel Renata Peñaherrera-Calle; José Miguel Llerena-Ramírez

2. Según la Organización Mundial de la Salud (OMS) el equipo de protección personal ayuda a reducir la propagación del covid-19 para los médicos que atienden pacientes con sospecha de contagio o pacientes que tienen el virus. La OMS dice, además, que el equipo de protección debe utilizarse de forma correcta y los médicos deben estar capacitados en eso.

3. Sonnenholzner; ex vicepresidente de la Republica, dijo el sábado 14 de marzo, que todos los profesionales de la salud pública y privada deberán aprobar en línea el programa de la Organización Mundial de la Salud para la emergencia del covid-19. Además, dijo que los miembros de salud pública están obligados a atender a todos los pacientes. Los que no cumplan con esa obligación, serán sancionados, dijo, la sanción podría ser impedir que en el futuro trabajen en el sector de la salud.

\section{DISCUSIÓN}

En el tema de la venta de insumos médicos y su repercusión dentro de la defraudación tributaria es de conocimiento público pero en la aplicación de este en medio de la emergencia sanitaria se considera que no son muy enérgicas las decisiones por medio de las autoridades competentes y por este motivo los ciudadanos creen viable que estas medidas o sanciones sean aplicadas de una manera más eficaz y que se cumpla lo tipificado en la norma, a pesar de esto, el Estado ecuatoriano ha empezado a combatir la corrupción de mejor forma y así poco a poco se ha conocido los todos los casos del país, lo cual concuerda con las investigaciones de (Haro-Velastegui, et al., 2019) y (De-La-Torre-Lascano, 2017).

\section{CONCLUSIONES}

Existió un verdadero impacto hacia todos los ecuatorianos ya que en medio de la emergencia sanitaria por el COVID19 puesto que la necesidad de una persona contagiada al necesitar insumos médicos tanto para ella como para el médico tratante, en este sentido el Derecho siempre ha establecido los limites previsibles de manera 
objetiva en el uso y goce de los mismos, de esta manera, el director o los encargados de las compras de dichos insumos sean estos con los precios justos establecidos por el mercado.

Al analizar el marco legal ecuatoriano se pudo evidenciar que existen una gran cantidad de leyes las cuales reconocen y garantizan la defraudación tributaria las cuales respaldan que el sobre precio en los insumos médicos y su repercusión en la sociedad cuando estos son revendidos o supuestamente comprados a un precio elevado.

Se logró analizar el conocimiento de algunos ecuatorianos sobre las normas aplicadas en la actualidad frente a dichas conductas, la cual ayudara a tener un conocimiento claro sobre lo que es una defraudación tributaria dentro del Ecuador.

\section{FINANCIAMIENTO}

No monetario.

\section{AGRADECIMIENTO}

A la Universidad Regional Autónoma de Los Andes; por motivar el desarrollo de la Investigación.

\section{REFERENCIAS CONSULTADAS}

Castro, M. (2020). Personal médico en Ecuador insiste en la falta de insumos de protección. [Medical personnel in Ecuador insist on the lack of protection supplies]. Recuperado de https://n9.cl/ncdh9

Código Orgánico Integral Penal, COIP. Registro Oficial Suplemento 180 de 10-feb.2014. Última modificación: 05-feb.-2018. Recuperado de https://n9.cl/xu3yj

Código Tributario. Registro Oficial Suplemento 38 de 14-jun.-2005. Última modificación: 21-ago.-2018. Recuperado de https://n9.cl/h59fu

Constitución de la República del Ecuador (2008). Título II. Derechos. Recuperado de https://n9.cl/ddge 
Myriam Valeria Ruiz-Salgado; Christel Renata Peñaherrera-Calle; José Miguel Llerena-Ramírez

De-La-Torre-Lascano, C. (2017). Relación existente entre paraísos fiscales, lavado de activos y defraudación tributaria. Un análisis desde la normativa de Ecuador. [Existing relationship between tax havens, money laundering and tax defraud. An analysis from the norms of Ecuador]. Revista de la Facultad de Derecho, (43), 3-31. https://dx.doi.org/10.22187/rfd2017n2a2

Haro-Velastegui, F. A., Delgado-Daquilema, M. R., Absalón-Wilberto, G. R., \& AriasGonzález, I. P. (2019). Defraudación tributaria y su incidencia en la sociedad [Tax fraud and its impact on society]. Ciencia Digital, 3(3.2), 258-265. https://doi.org/10.33262/cienciadigital.v3i3.2.749

Organización Mundial de la Salud, OMS. (2020). Uso racional del equipo de protección personal frente a la COVID-19 y aspectos que considerar en situaciones de escasez graves. [Rational use of personal protective equipment against COVID19 and aspects to consider in severe shortages]. Recuperado de https://n9.cl/08wky

Peña, L. (2013). Ética y servicio público. [Ethics and public service]. Plaza y Valdés. Madrid. España.

Secretaría General de La República (2020). Otto Sonnenholzner: "El mayor enemigo debe ser el virus y no la desobediencia". [Otto Sonnenholzner: "The greatest enemy must be the virus and not disobedience"]. Recuperado de https://n9.cl/d9ia

Zevallos, J. (2020). Ecuador tiene 121 millones de dólares para enfrentar la emergencia sanitaria del Covid-19, dice el nuevo Ministro de Salud. [Ecuador has 121 million dollars to face the health emergency of Covid-19, says the new Minister of Health]. Recuperado de https://n9.cl/fzOp 